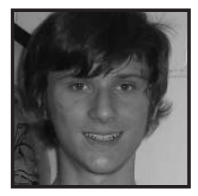

\title{
The High Wire of Success
}

\author{
Jordan Quenneville, St George's School of Montreal
}

\section{ABSTRACT (Press Here for Sound)}

This article focuses on the need for balance in the educational system and the importance of extracurricular activities to student growth. Using examples from St. George's School of Montreal, the author shows how balance can be implemented in the curriculum. The article also addresses the different ways St. George's implements its six main principles into both the curriculum and extracurricular activities.

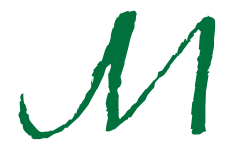

any people are concerned about the future. Some people worry about the economy, some worry about the environment, and some people worry about their career. But many people worry about their children's future. Educators know that the key features of a meaningful learning environment are the engagement of students in the classroom as well as extracurricular activities. As a student at St. George's, I have my own opinion on why these aspects of education are important and also how we can help improve them. First, let us take a look at this school. Kids at St. George's seem to love the extracurricular activities and their classes. Now the million-dollar question is: Why?

Many schools have their own specialties. Some are more sports oriented; some are arts or science oriented. Many people wonder which school style is better for students: the arts allow students to be creative and think independently. Sports give students confidence and teach them the importance of teamwork and cooperation. I believe that the fundamental issue is that schools have gotten too focused on maintaining a certain image or reputation as being a good sports or academic school, and the students suffer as a result. However, I believe that the success of the St. George's model is balance. 
St. George's is founded on six main principles: Health must come first; Learning comes from doing; The classroom should be freed from unnatural restraints; Adapt education to the differences of the individual child; Group-consciousness and social-mindedness should be developed; The child should have abundant opportunity for creative expression (Cross, 1933). This article focuses on one of these principles: Adapt education to the differences of the individual child. This is one of the core principles of St. George's and represents how all the teachers there are trained.

Philosophies can be very abstract; they are not meaningful unless they are implemented. The atmosphere around St. George's is unique. The six main principles are implemented almost everywhere. There are vending machines full of healthy snacks (Health must come first), the gym is usually open at lunch (Learning comes from doing) and the teachers are available during all of the students' free time and are always willing to help (The classroom should be free from unnatural restraints). The school itself is somewhat small: only 315 students are currently enrolled in the high school. The building is big enough to accommodate everyone, but small enough to feel intimate. There are four floors, with the second and fourth floors reserved for classes. The first and third are for lockers and administration. In the student lounge, kids hang out on couches, enjoy snacks from vending machines, and play foosball. All in all, the school feels very comfortable and secure, like a home. Everybody knows everybody. It can get crowded when everyone changes classes, but that is only for ten minutes.

The atmosphere is also unique at St. George's because we have such a diverse population. While the tuition might be steep, approximately $50 \%$ of the students receive student aid, a little known fact ( $M$. Webster, personal communication, April 30, 2009). Thus, the students are exposed to a variety of people from all walks of life. We also have a huge international student population, which enriches our understanding of cultures. And of course, as one of the few co-ed private schools in Montreal, young men and women learn to work and socialize together. Policies which stimulate diversity in our school are all a part of the balanced approach to the creation of "responsible world citizens" (J. Officer, personal communication, June 15, 2009).

Now that I have described the atmosphere and population of St. George's, I would like to focus on the balanced curriculum. The overall curriculum is based on the principle that every students' education should be adapted for their personality and their learning needs. Naturally, St. George's follows the requirements of the Ministère de l'Éducation, du Loisir et du Sport (MELS). However, certain classes 
become optional after Grade 9. These courses include: Art, Drama, Music, Science, and Computer Arts. This allows students to have some knowledge in all fields, which lets them make better class and career choices in the future. After Grade 9, a variety of more academic optional courses also become available to the student, such as: Marine Biology, Physics, Chemistry, AP Psychology, Media and Humanities. As the students grow, they are given more choice over their courses. This curriculum creates more motivated students and a higher quality of education, while still teaching the students about all areas of life.

Now that I have discussed St. George's curriculum, the next step is the classroom environment. When students are young, they require more structure and discipline to maintain an optimal learning level. Naturally, the junior classes at St. George's reflect this. But as students get older, the teachers become more like "learning partners" than stereotypical teachers. The teachers at St. George's are in the midst of a fiveyear professional development plan focusing on Differentiation of Instruction ( $M$. Webster, personal communication, April 30, 2009). This means that the teachers recognize that each student's needs are different and that they need to create a different path for various students to reach the same goal. They create these different paths based on the students' interests, how they learn best and their degree of learning readiness. The result is a classroom in which everyone is striving for the same goals, but in ways that are adapted for individuals. This way, everyone understands what they are doing, and why they are doing it, so learning can move at an accelerated academic rate.

Now I am sure some of you are thinking that all this child-centered and custom-made learning could be a bad idea. If a school does not specialize in a certain way, then the students will have no forte and have a harder time succeeding in CEGEP and university, you might think. In fact, the opposite is true. At St. George's it is not only the academic courses that build the student, but also the extracurricular activities. By providing a balance of extracurricular activities, students can specialize in areas in which they are interested. This way, students have the opportunity to go into whatever activity they want and enjoy it. If the students enjoy the activities they are in, they will learn better, faster and the projects they are working on will show improvement. Also, by engaging in after-school activities, students will generally learn better time-management skills and their class marks will improve as well. Yet the key to the balanced extracurricular style is good planning.

The extracurricular activities at St. George's reflect this approach. There are sports activities: everything from basketball to dodge-ball to badminton to yoga. 
There are activities in the arts: Stage Crew, drama productions, Music and even AP Art. Then there are also the sciences: S.O.S. (Students on Sustainability, the school's green committee), Science Fair, Robotics, Math Trail and Physics Challenge. There are even school trips that help teach students in a fun and interesting way like the Water Quality trip, Stratford and New York drama trips, the Honduras marine biology trip and even the India trip. The India trip reflects another of the school's six founding principles, learning by doing. It is a trip which immerses the students in the local Indian culture by living at a home for orphaned girls, which the school supports, and also by traveling to other major cities in India. These kinds of trips are a privilege for a few. Many of these trips and activities were started by teachers; and they continue to create new activities throughout the year, such as the recent addition of an antistress workshop, designed in response to students' needs.

But the most important aspect about all these extracurricular activities is choice. This way only the students who want to be in a certain activity participate, making the students and teachers happy as well as producing a high-quality experience. However, the school does make it mandatory to participate in at least one sport and one Arts or Science activity (this can also be an activity outside the school). This is important because it ensures that the school produces a well-rounded student with a variety of skills. Basically, the St. George's extracurricular program has two levels of balance: the first is variety of extracurricular activities and the second is the requirement of these activities.

I love it when I find interest in a new topic and there is already a class or extracurricular activity waiting for me. It allows students to fully reach their potential and let their minds grow in any direction they wish. I feel passionate about my work, and the activities that I participate in strengthen that and open my eyes to the world beyond academics. I have a little bit of everything on my academic plate and am proud of that. I think that balance is important in all aspects of life. I have been in St. George's since kindergarten. My parents worked very hard to place me in this school, and I have worked hard to stay here. But that is only half the story. The teachers and administration care immensely about their students; they make sure you reach your full potential, no matter what it is. I do not think I would have it any other way. In the circus of the educational system, it is hard to cross the high wire without balance. 


\section{References}

Cross, D. (1933). Some principles upon which the work of St. George's School is based. St. George's Prospectus, 4-8.

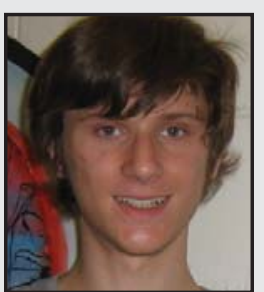

Jordan Quenneville is a Grade 11 student at St. George's High School of Montreal. He greatly admires nature in all its complexity and balance, and is particularly interested in biology and quantum mechanics. Jordan has been accepted in the Health Sciences program at Dawson College. 